PROMEDIA (PUBLIC RELATION DAN MEDIA KOMUNIKASI) ISSN 2460-9633

Volume Ke-6 No. 1, 2020, Randy, dkk, Budaya Literasi, hal 59 - hal 98

\title{
Budaya Literasi dalam Perspektif Tanggung Jawab Sosial
}

Culture of Literacy in Social Responsibility Perspective

\section{David Randy \\ Nawiroh Vera \\ Umaimah Wahid}

Universitas Budi Luhur

Jl. Ciledug Raya, Petukangan Utara, Pesanggrahan, Jakarta Selatan

1871600035@student.budiluhur.ac.id

nawiroh.vera@budiluhur.ac.id

umaimah.wahid@budiluhur.ac.id

Dikirim: 30 Desember 2020, Direvisi: 30 Mei 2020, Diterima: 30 Mei 2020, Terbit: 18 Juni 2020

Sitasi: Randy, D; Vera, $N \&$ Wahid, U. (2020). Budaya Literasi dalam Persepktif Tanggung Jawab Sosial. PRoMEDIA. Volume 6 (1), Juni 2020, hal 59- hal 98

\begin{abstract}
Throughout 2019, Indonesia was confronted with a number of mass actions that led to riots. In many discussions on mainstream media platform as well as academic institutions, the circulation of hoaxes and fake news on social media are often used as scapegoats. President of the Indonesian Anti-Defamation Society (Mafindo), Anita Wahid explained, in 2015, there was an average of 10 hoaxes circulated in Indonesia per month. This number increased to 27 per month in 2016, 59 per month in 2017, and 96 per month in 2018. According to Central Connecticut State University, in 2016, Indonesia was on the 60th position (out of 61 countries) regarding literacy and literate behaviour. Based on Aisah, Hasra, and Sumiati's finding, it is known that as many as 61 percent of 184 respondents (Indonesian undergraduate students) couldn't identify one of the three fake news that was presented. Meanwhile, according to Dr Quinton Temby's analysis, the protests on May 21-22 in Jakarta, which led to riots, were the result of online disinformation. This type of chaos was the first time that had ever happened among democratic countries. The dependence of the Indonesian public on the social media platform can indicate a decline in public trust for the
\end{abstract}


mainstream media. Temby claimed that this happened because most of Indonesian's mainstream media were too sympathetic to the government. On this paper, the authors examine the phenomenon of the circulation of hoax and fake news in Indonesia through a multi-modal analysis. We started the study by conducting background analysis (literature reviews) on the culture of literacy in Indonesia, continuing with frame analysis of METRO TV's news (allegedly as one of the pro-government media), then analysing the findings in the social responsibility perspective. Results of the analysis showed an increase in the number of hoaxes and false news' circulation in Indonesia. For this reason, to combat its circulation, the government's commitment is needed to foster a literate culture. The mainstream media need to increase public trust through more educative and critical programs. Social media companies need to be more active and responsive in preventing and combating the circulation of hoaxes and fake news. At the same time, the Indonesian public needs to educate themselves by increasing their understanding and knowledge.

Keywords: Framing Analysis, Fake News, Hoax, Culture of Literacy, Social Responsibility Theory.

\section{Abstraksi}

Sepanjang tahun 2019, Indonesia dihadapkan dengan sejumlah aksi massa yang berujung kericuhan. Dalam banyak diskusi di media massa mau pun institusi akademik, peredaran hoax dan fake news di media sosial sering dijadikan sebagai kambing hitam. Presiden Masyarakat Anti Fitnah Indonesia (Mafindo), Anita Wahid menerangkan bahwa pada 2015 rata-rata 10 hoax beredar di Indonesia per bulannya. Jumlah tersebut meningkat menjadi 27 per bulan pada 2016, 59 per bulan pada 2017, dan 96 per bulan pada 2018. Hasil studi di Universitas Negeri Central Connecticut tentang budaya literasi global pada 2016, menempatkan Indonesia di peringkat 60 dari 61 negara yang diteliti. Dari penelitian Aisah, Hasra, dan Sumiati, diketahui sebanyak 61 persen dari 184 
responden (mahasiswa Indonesia) tidak dapat mengidentifikasi 1 dari 3 fake news yang ditampilkan. Sementara itu, Dr. Quinton Temby berpendapat bahwa aksi massa di Jakarta yang berujung kericuhan pada 21-22 Mei lalu ialah akibat dari disinformasi online. Kericuhan semacam itu merupakan yang pertama kali terjadi di negara demokrasi. Ketergantungan sejumlah rakyat Indonesia terhadap platform media sosial merupakan indikasi penurunan keperayaan publik kepada media mainstream. Temby mengklaim bahwa hal tersebut terjadi karena sebagian besar media mainstream Indonesia terlalu bersimpati kepada pemerintah. Pada penelitian ini, penulis mengkaji fenomena peredaran hoax dan fake news di Indonesia melalui analisis multi-modal. Kami memulai dari analisis latar belakang (studi pustaka) tentang budaya literasi di Indonesia, dilanjutkan dengan analisis framing berita METROTV (yang diduga sebagai salah satu media massa pendukung pemerintah), kemudian menganalisis temuan-temuan dalam perspektif tanggung jawab sosial. Hasil analisis menunjukkan adanya peningkatan jumlah sirkulasi hoax dan fake news di Indonesia. Untuk itu, dalam upaya memerangi peredarannya diperlukan komitmen pemerintah dalam menumbuhkan budaya literasi. Media massa mainstream perlu meningkatkan kepercayaan publik melalui tayangan-tayangan yang lebih edukatif dan kritis. Perusahaan media sosial perlu berperan lebih aktif dan responsif dalam mencegah dan melawan peredaran hoax dan fake news. Di saat yang sama, masyarakat Indonesia perlu mengedukasi diri melalui peningkatkan pemahaman dan pengetahuan secara mandiri.

Kata Kunci: Analisis Framing, Budaya Literasi, Fake News, Hoax, Teori Tanggung Jawab Sosial.

\section{PENDAHULUAN}

Pasca terselenggaranya berbagai kegiatan berskala internasional di 2018, segala peristiwa yang terjadi di Indonesia kian mendapatkan perhatian dunia internasional. Media asing 
seperti ramai-ramai mengirimkan jurnalis untuk memberitakan musibah tsunami di Palu dan Donggala pada September 2018 lalu. Serangkaian peristiwa menjelang pemilihan presiden 2019 juga mendapat banyak sorotan. Sayangnya, akhir-akhir ini, narasi yang tadinya berisi puji-pujian sebagian mulai berubah.

Jakarta riots: Indonesian president says he will not tolerate threats to unity (The Guardian, 22/05/2019)

Photos: Deadly Post-election Riots in Indonesia

(The Atlantic, 23/05/2019)

Police Violence in Indonesian Riots Sparks Human Rights Debate (VOA, 28/05/2019)

Who was behind the Jakarta riots?(The Straits Times, 29/05/2019)

Indonesian police beat protesters during deadly Jakarta riots: Amnesty (CNA, 26/06/2019)

Menariknya, dari sekian banyak peristiwa yang terjadi di Indonesia, yang menjadi narasi bahasan sejumlah media asing ialah aksi massa yang berujung kericuhan. Sementara peristiwa dengan narasi yang positif cenderung tidak masuk dalam pemberitaan media asing tersebut.

Indonesian human rights lawyer wins prize for West Papua work (RNZ, 24/10/2019)

Rights group: 10 unlawfully killed in Indonesia election riots (Aljazeera, 29/10/2019)

Today we stand on Indonesian land corrupted by oligarchy: Student protests rock Indonesia (India Today, 08/11/2019)

Anger on campus: Behind the student protests that have rocked Indonesia (The Jarusalem Post, 10/11/2019)

RPT-Indonesia needs to urgently establish data protection lawminister (Reuters, 18/11/2019)

Tidak dapat dipungkiri memang, sepanjang tahun 2019, Indonesia acapkali dihadapkan dengan aksi-aksi massa yang 
berujung kericuhan. Pada sejumlah diskusi di media massa maupun institusi akademik, peredaran liar hoax dan fake news di media sosial sering kali dijadikan sebagai kambing hitam. Menurut Presiden Masyarakat Anti Fitnah Indonesia (Mafindo), Anita Wahid (voanews.com, 25/10/2018), frekuensi peredaran hoax di Indonesia mengalami peningkatan signifikan dari tahun ke tahun. Pada 2015, rata-rata sebanyak 10 hoax yang beredar per bulan. Meningkat menjadi 27 per bulan pada 2016, 59 per bulan pada 2017, dan 96 per bulan pada 2018.

Dr. Quinton Temby (South China Morning Post, 09/09/2019) berpendapat bahwa aksi massa di Jakarta yang berujung kericuhan pada 21-22 Mei lalu ialah akibat dari disinformasi online. Menurutnya, ini kali pertama disinformasi pada media sosial menciptakan kerusuhan pemilu di sebuah negara demokrasi. Peneliti dari ISEAS-Yusof Ishak Institute Singapura itu menambahkan, ketergantungan sejumlah rakyat Indonesia terhadap platform media sosial merupakan akibat dari sebagian besar media mainstream Indonesia yang terlalu bersimpati kepada pemerintah.

Pernyataan Temby bukan tidak berdasar, hal ini dapat dilihat dari dukungan sejumlah pemilik media massa kepada presiden petahana menjelang pemilihan umum April lalu. Seperti yang dilansir Tempo (10/09/2018), terdapat tiga pemilik media massa yang secara terbuka memberikan dukungannya kepada calon presiden nomor urut 1, Joko Widodo. Ketiga pemilik media 
tersubut ialah Erick Thohir dengan Mahaka Grup (setidaknya 14 media massa), Hary Tanoesoedibjo dan MNC Grup (setidaknya 12 media massa), serta Surya Paloh dan Media Grup (setidaknya 8 media massa).

Sudibyo (2000:122) berpendapat bahwa isi media ditentukan oleh kekuatan-kekuatan ekonomi dan potitik di luar media. Faktor seperti pemilik media, modal, iklan, dan regulasi pemerintah dianggap lebih menentukan bagaimana media mengkonstruksi sebuah realitas. Ketentuan-ketentuan media meliputi peristiwa apa saja yang bisa atau tidak bisa ditampilkan dalam pemberitaan, atau ke mana kecenderungan pemberitaan itu hendak diarahkan. Maka, dapat dipahami jika sejumlah pakar komunikasi sempat khawatir akan pembingkaian yang bias oleh grup media yang dimiliki oleh pendukung salah satu pasangan calon.

Berdasarkan hasil studi Universitas Negeri Central Connecticut tentang budaya dan kebiasaan literasi pada 2016, Indonesia menduduki peringkat 60 dari 61 negara (voanews.com, 25/10/2018). Senada dengan data di atas, hasil penelitian Aisah, Hasra, dan Sumiati (ISLLAE, 2019) menunjukkan, sebanyak 112 (61 persen) dari 184 responden (mahasiswa Indonesia) tidak dapat mengidentifikasi 1 dari 3 fake news yang ditampilkan.

Di tengah pertumbuhan dan peredaran hoaks yang semakin liar, ada kecenderungan saling tuding dan melempar tanggung jawab dari sejumlah unit sosial masyarakat di Indonesia. Hal yang lebih ironis ialah ketika media massa ramai-ramai 
mempertontonkan peristiwa tersebut kepada publik. Sebut saja kutipan pernyataan Sekretaris Utama Badan Siber dan Sandi Negara (BSSN), Syahrul Mubarak, yang dilansir oleh Berita Satu, (15/03/2019). Di dalam pernyataannya, Mubarak meminta penyedia platform media sosial (medsos) untuk ikut bertanggung jawab terhadap maraknya peredaran berita hoax serta ujaran kebencian di medsos. Akan tetapi, pada berita tidak ada informasi tambahan mengenai upaya apa yang telah dan akan dilakukan BSSN dalam memerangi hoaks.

Hasil studi Universitas Oxford yang dilansir The Washington Post (02/10/2019) menunjukkan bahwa pemerintah dan partai politik di 70 negara melakukan kampanye manipulatif di media sosial, meningkat dari 28 negara pada tahun 2017. Terlepas dari pernyataan Sekretaris Utama BSSN, laporan investigasi Strick dan Syavira (BBC News, 11/10/2019) mengekspos sejumlah akun yang terindikasi melakukan kampanye di media sosial. Akun-akun tersebut dituding mempromosikan agenda pro-pemerintah Indonesia di Papua. Laporan yang sama menyatakan bahwa terdapat 100 akun di Facebook yang memiliki hubungan dengan InsightID, konsultan media lokal yang berkantor di Jakarta. Akunakun tersebut diketahui telah menghabiskan sebanyak \pm USD 300000 ( \pm Rp 4,2 miliar) untuk beriklan di Facebook.

Ditemukannya akun-akun palsu yang menyebarkan pernyataan yang sama tentang Papua di media sosial mengindikasikan adanya kampanye manipulatif menggunakan 
robot (ibid). Tindakan Facebook yang menghapus akun-akun palsu temuan dari hasil investigasi BBC dan Australian Strategic Policy Institute (ASPI) itu mendapatkan bayak dukungan. Sejumlah pihak lainnya menganggap tindakan tersebut sebagai kegiatan "bersihbersih" menjelang kesaksian Mark Zuckerberg di hadapan lembaga legislatif Amerika Serikat pada 23 Oktober lalu.

Fenomena dan temuan-temuan yang ada memunculkan beberapa pertanyaan, yaitu:

1. Bagaimana tingkat budaya literasi di Indonesia?

2. Bagaimana sistem sosial masyarakat dalam menanggapi sirkulasi hoax dan fake news di Indonesia?

Studi ini bertujuan untuk mengkaji fenomena peredaran hoax dan fake news yang marak terjadi di media sosial Indonesia beberapa waktu terakhir. Untuk menjawab kedua pertanyaan di atas, penulis melakukan analisis latar belakang berupa studi pustaka tentang budaya literasi di Indonesia, melaksanakan analisis atas framing media pendukung pemerintah (METROTV), dan membahas data-data yang diperoleh dari sudut pandang tanggung jawab sosial. Harapannya, hasil studi ini dapat menyumbangkan serangkaian rumusan solusi untuk dipertimbangkan dalam rangka penyelesaian masalah terkait peredaran hoax dan fake news di media sosial, khususnya di Indonesia. 


\section{TINJAUAN PUSTAKA}

\section{A. Budaya Literasi}

Hofstede et al. dalam Mulyana (2012:11) mendefinisikan budaya sebagai, "collective programming of the mind which distinguishes the member of the group or category of people from others." Dapat diartikan bahwa, budaya merupakan pola pikir kolektif yang membedakan anggota sebuah kelompok atau kategori dengan orang lain. Samovar et al. dalam Mulyana (ibid) berpendapat, lima kategori budaya yang mempengaruhi komuikasi orang dari budaya tertentu ialah sejarah, agama, nilai-nilai, organisasi sosial, dan bahasa.

Kellner dan Share dalam Bastani, Shiri, dan Farhangi (2019:43) menjelaskan, "Literacy involves gaining the skills and knowledge to read, interpret, produce texts and artefacts, and to gain the intellectual tools and capacities to fully participate in one's culture and society." Dengan kata lain, literasi meliputi kemampuan untuk memperoleh keterampilan dan pengetahuan untuk membaca, menafsirkan, memproduksi teks dan artefak, serta kemampuan untuk memperoleh alat dan kapasitas intelektual agar dapat berpartisipasi penuh dalam budaya dan masyarakat.

Kementerian Pendidikan dan Kebudayaan mendefinisikan literasi budaya sebagai kemampuan dalam memahami dan bersikap terhadap kebudayaan Indonesia sebagai identitas bangsa (Pratiwi dan Asyarotin, 2019:67). Dengan demikian, budaya literasi merupakan pembentukan pola pikir kolektif yang 
berorientasi pada peningkatan kemampuan untuk memperoleh keterampilan dan pengetahuan dalam membaca, menafsirkan, memproduksi teks dan artefak, serta peningkatan kemampuan untuk memperoleh alat dan kapasitas intelektual agar dapat berpartisipasi penuh dalam menciptakan nilai tambah di masyarakat.

\section{B. Politik Ekonomi Media}

Hicks dalam Cardinale dan Scazzieri (2018:2) berargumentasi bahwa ekonomi politik adalah objek studi jenis investigasi. Karakterisasi sebelumnya dari ekonomi politik sebagai objek studi dikaitkan dengan pergeseran konsentrasi perhatian berbagai aspek antara ekonomi dan negara. Sudibyo (2000:120) berpendapat bahwa isi media ditentukan oleh kekuatan-kekuatan ekonomi dan potitik di luar media. Menurutnya, jika dilihat dari sudut pandang politik-ekonomi, faktor seperti pemilik media, modal, iklan, dan regulasi pemerintah sedikit banyak menentukan bagaimana konstruksi realitas yang diproduksi media.

Tracy dalam Cardinale dan Scazzieri (2018:2) berpendapat, "Political economists have typically adopted a view of the economy as a set of coordinated exchanges or as a system of interdependent production activities coordinated through the division of labour." Ekonom politik biasanya mengadopsi pandangan tentang ekonomi sebagai seperangkat pertukaran yang terkoordinasi atau sebagai sistem kegiatan produksi yang saling tergantung yang dikoordinasikan melalui pembagian kerja. 
Cardinale dan Scazzieri (2018:3) mendefinisikan politik ekonomi sebagai ilmu mengenai kesejahteraan dan berkaitan dengan usaha-usaha yang dilakukan manusia untuk memenuhi dan memuaskan keinginannya. Sementara ekonomi politik media memfokuskan pada kajian tentang hubungan antara struktur ekonomi-politik, pergerakan industri media, dan ideologi organisasi media. Perhatian penelitian ekonomi politik berpusat pada kepemilikan, kontrol serta kekuatan pasar media. Dari pandangan tersebut, industri media massa diasumsikan sebagai sistem ekonomi yang berhubungan erat dengan sistem politik.

Dari berbagai pandangan tersebut dapat dipahami bahwa berita yang diproduksi sebuah media memiliki relasi ekonomi dalam struktur perusahaan bisnis. Pola dan jenis pemberitaan ditentukan oleh kepentingan-kepentingan ekonomi yang menguasai perusahaan media. Dengan demikian, teori ekonomi politik media ini penting untuk dipahami agar dapat mengkaji dominasi kepentingan ekonomi, kepemilikan media, dan/ kepentingan politik terhadap konstruksi realitas yang dihasilkan oleh media tersebut. Penulis menggunakan teori ini sebagai teori pelengkap dalam pembuktian adanya keberpihakan media yang diamati.

\section{Framing Model Edelman}

Edelman dalam Eriyanto (2012:185) berpendapat bahwa apa yang kita ketahui tentang dunia sangat tergantung pada bagaimana kita membingkai dan menafsirkan realitas. Edelman 
mensejajarkan framing sebagai kategorisasi. Artinya, media mengarahankan perspektif khalayak dalam memahami sebuah realitas tertentu melalui menggunakan kata-kata tertentu.

Eriyanto (2012:186) menjelaskan kategorisasi dalam pandangan Edelman sebagai abstraksi dan fungsi dari pemikiran. Menurutnya, kategorisasi yang di maksud oleh Edelman secara ideal bertujuan untuk membantu manusia memahami realitas yang beragam dan tidak beraturan menjadi realitas yang mempunyai makna. Namun pada praktiknya, seringkali kategorisasi yang dimunculkan hanyalah menguntungkan media dan/ kelompok kepentingan tertentu.

Dengan demikian, kategorisasi dapat diartikan sebagai suatu penyederhanaan atas realitas yang kompleks agar dapat dipahami dengan menekankan satu sisi atau dimensi dan mengesampingkan sisi atau dimensi lain. Kategorisasi merupakan alat bagaimana realitas dipahami dan dihadirkan dalam benak khalayak. Kategorisasi alternatif dapat merubah makna. Perubahan itu bukan ditentukan atau diakibatkan oleh perubahan realitas atau peristiwa, melainkan perubahan dari abstraksi pikiran yang menentukan bagaimana realitas hendak dipahami. Pada penelitian ini, penulis menggunakan teori framing sebagai pisau analisis untuk membutikan adanya kecenderungan media dalam mengkonstruksi sebuah realitas. 


\section{Tanggung Jawab Sosial}

Tanggung jawab sosial dapat dilihat dari berbagai sudut pandang. Dari sudut pandang bisnis, tanggung jawab sosial sering dideskripsikan sebagai pelaksanaan kegiatan sosial oleh perusahaan dan/ institusi untuk menciptakan citra prositif, meningkatkan loyalitas, dan/ sebatas mempertahankan kepercayaan pelanggan. Carsrud dan Brännback (2007:98) berasumsi bahwa komsumen akan lebih loyal dan lebih bersedia untuk membeli lebih banyak produk dari perusahaan yang tidak hanya mencari keuntukan bisis, tetapi juga memperhatikan kesejahteraan masyarakat dan lingkungan sekitar.

Pada bidang jurnalistik tanggung jawab sosial dilihat dari peran media massa di masyarakat. Siebert et al. (1956:74) merumuskan tanggung jawab sosial media massa kedalam enam fungsi, yaitu:

1. Fungsi informasi

Melalui penayangan program diskusi atau debat yang informatif dan berorientasi pada kepentingan publik.

2. Fungsi pendidikan

Melalui penayangan program yang berorientasi pada kemandirian publik.

3. Fungsi pengawasan

Melalui penayangan program yang kritis terhadap kebijakan pemerintah yang tidak berorientasi pada kepentingan publik.

4. Fungsi ekonomi 
Menyediakan layanan yang mempertemukan penjual dengan pembeli melalui medium iklan.

5. Fungsi hiburan

Menyediakan program hiburan yang baik, yaitu yang meningkatkan pengetahuan dan wawasan publik.

6. Fungsi imparsialitas

Mempertahankan stabilitas finansial agar terbebas dari tekanan pihak-pihak berkepentingan.

Folkens dan Schneider (2019:159) berpendapat bahwa tanggung jawab sosial merupakan kerangka kerja etis. "Individuals are accountable for fulfilling their civic duty; the actions of an individual must benefit the whole of society." Menurut mereka, individu bertanggung jawab untuk memenuhi tugas kewarganegaraan mereka yang mana tindakan seseorang harus bermanfaat bagi seluruh masyarakat. Invernizzi dalam Folkens dan Schneider (ibid) menjelaskan bahwa tanggung jawab sosial tidak hanya berlaku untuk organisasi bisnis, tetapi juga untuk semua aktor yang tindakannya mempengaruhi lingkungan. Untuk itu, dalam rangka merumuskan solusi untuk memerangi peredaran hoax dan fake news, penulis memusatkan perhatian pada pemerintah, media massa, dan masyarakat (publik).

\section{METODE PENELITIAN}

\section{A. Jenis Penelitian}

Studi ini menggunakan pendekatan kualitatif dengan teknik analisis multi-modal. Penelitian didasari karena adanya sejumlah 
kericuhan di Indonesia yang diduga terjadi akibat sirkulasi hoax dan fake news di media sosial (disinformasi online). Beranjak dari fenomena tersebut, penulis mengkomparasi data hasil penelitian dan laporan investigasi terkait peredaran hoax dan fake news di Indonesia, serta tingkat budaya literasi masyarakat Indonesia.

Salah satu hasil studi pustaka mengidikasikan adanya faktor di luar media sosial yang turut mempengaruhi sirkulasi hoax dan fake news, yaitu kecurigaan atas liputan media mainstream yang bias. Untuk membuktikan kecenderungan media, penulis melakukan analisis framing media televisi yang dianggap sebagai pendukung pemerintah (METROTV) melalui tabulasi bingkai berita dengan kata kunci "Jokowi” pada periode 16-30 Oktober 2019 (sebelum dan setelah pengumuman kabinet).

Seluruh data temuan kemudian dianalisis dalam perspektif tanggung jawab sosial. Dari hasil analisis deskriptif tersebut, penulis merumuskan sejumlah tawaran solusi dalam upaya memerangi peredaran hoax dan fake news di Indonesia.

\section{B. Pengumpulan Data}

Data diperoleh dari hasil studi pustaka terkait hoax dan fake news di Indonesia, serta analisis berita-berita METROTV dengan kata kunci "Jokowi" pada periode 16-30 Oktober 2019 (sebelum dan setelah pengumuman kabinet). Adapun hasil studi pustaka sebagai berikut: 
a. Peredaran Hoax dan Fake News di Indonesia

1) Presiden Masyarakat Anti Fitnah Indonesia (Mafindo), Anita Wahid dalam voanews.com (25/10/2018) melaporkan peningkatan frekuensi peredaran hoax di Indonesia dari tahun 2015-2018. Menurutnya pada 2015, rata-rata sebanyak 10 hoax yang beredar per bulan. Meningkat menjadi 27 per bulan pada 2016, 59 per bulan pada 2017, dan 96 per bulan pada 2018.

2) Mason, Kruta dan Stoddard (JMLE, 2018) menyimpulkan, dinamika media sosial sengaja dibuat untuk menguasai perhatian pengguna untuk memperkuat sirkulasi fake news.

3) Mudjiyanto (PROMEDIA, 2019) menjelaskan bahwa berita/informasi hoaks yang digulirkan oleh sumbersumber yang tidak jelas keberadaannya bertujuan untuk menyebarkan kebencian, black campaigne, merubah cara berpikir (mindset) masyarakat dalam menyikapi suatu permasalah yang sedang booming (trending topic) sehingga dapat menyesatkan bagi pemirsa, pembaca, dan melihat yang tidak cerdas dalam menganalisa isi atau konten berita/informasi tersebut.

4) Temby dari ISEAS-Yusof Ishak Institute Singapura dalam South China Morning Post (09/09/2019) menyatakan bahwa aksi massa di Jakarta pada 21-22 Mei 2019 ialah akibat dari disinformasi online. Menurutnya, kericuhan pemilu semacam ini merupakan kali pertama terjadi di 
sebuah negara demokrasi. Temby mengklaim bahwa ketergantungan publik kepada media sosial ialah akibat adanya bias pada tayangan media mainstream Indonesia yang dianggap terlalu bersimpati kepada pemerintah.

5) Hasil penelitian Fauzi (PROMEDIA, 2018) menunjukkan bahwa seorang informan melakukan penyaringan atau tidak terhadap informasi hoax dan hate speech tergantung pada kesesuaian visi dan persepsi. Jika konteks informasi tidak memiliki hubungan dengan dirinya maka informan memilih mengabaikannya.

6) Hasil survei Mastel dalam Herawati (PROMEDIA, 2016) menunjukkan, pengguna internet diterpa berita hoax sebesar 44,30\% setiap hari dan mendapatkan lebih dari satu hoax dalam sehari sebesar 17,20\%.

7) Peneliti dari Universitas Oxford dalam The Washington Post (02/10/2019) mempublikasikan indikasi pelaksanaan kampanye manipulatif di media sosial yang dilakukan oleh pemerintah dan partai politik di 70 negara. Jumlah tersebut meningkat dari 28 negara pada tahun 2017. 


\section{Different accounts, same content}

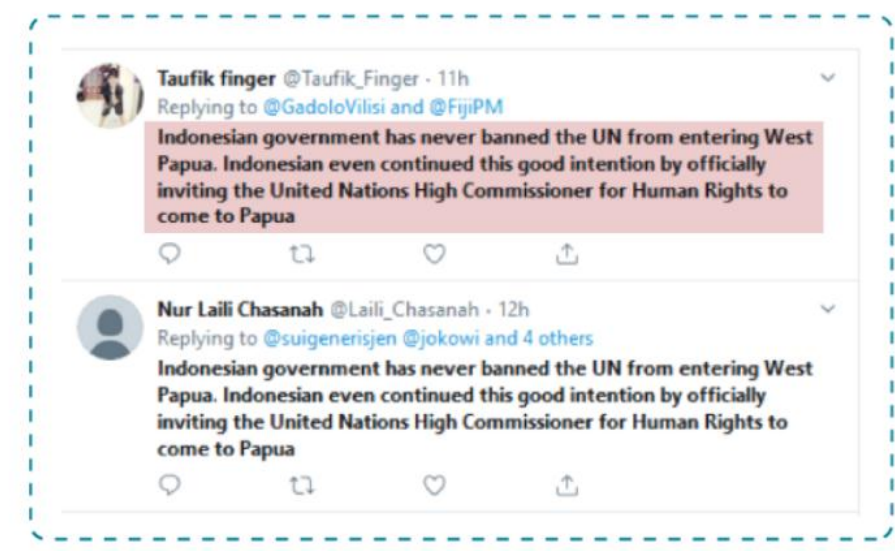

They only post content about Papua and numerous accounts post exactly the same thing.

8) Laporan investigasi kolaboratif antara BBC dan Australian Strategic Policy Institute (ASPI) menyebutkan indikasi kampanye media sosial untuk mempromosikan agenda propemerintah di Papua (BBC News, 11/10/2019). Hasil investigasi tersebut mengklaim temuan 100 akun Facebook palsu yang memiliki keterkaitan dengan InsightID, perusahaan konsultan media yang berkantor di Jakarta. Akun-akun tersebut dituding telah menghabiskan sebanyak \pm USD 300000 ( \pm Rp 4,2 miliar) untuk mengiklankan narasi pro-Jakarta. Investigasi juga mengungkap adanya akun-akun robot pro-Jakarta di twitter. 
b. Budaya Literasi di Indonesia

1) Hasil studi Universitas Negeri Central Connecticut tentang budaya literasi global pada 2016 menunjukkan, Indonesia berada di peringkat 60 dari 61 negara yang diamati (voanews.com, 25/10/2018).

2) Hasil penelitian Wardani (Jurnal Unimed, 2018) menyatakan, tingkat pendidikan politik kelompok pemilih pemula di Indonesia masih rendah. Hal ini membuat pemilih pemula rentan dijadikan sasaran untuk dimobilisasi oleh kepentingan-kepentingan tertentu.

3) Hasil studi Lailiyah, Yuliyanto, dan Pradhana (ICENIS, 2018) juga menunjukkan adanya keterlibatan yang kuat antara kaum muda Indonesia dengan media sosial. Akan tetapi tingginya penggunaan media sosial tidak dilengkapi dengan kesadaran politik yang mumpuni, akibatnya kaum muda Indonesia rentan menjadi sasaran "kehebohan politik yang kotor".

4) Menurut Herlina dan Husada (PROMEDIA, 2019), literasi yang rendah meningkatkan potensi remaja menjadi korban kejahatan siber.

5) Hasil penelitian Aisah, Hasra, dan Sumiati (ISLLAE, 2019) menunjukkan, sebanyak $61 \%$ dari 184 responden (mahasiswa Indonesia) tidak dapat mengidentifikasi 1 dari 3 fake news yang ditampilkan. 


\section{PEMBAHASAN}

\section{A. Berita "Jokowi" di METROTV sebelum Pengumuman}

\section{Kabinet}

Dalam Pemberitaan Jokowi di Metro TV sebelum Pengumuman diperoleh data sebagai berikut:

1) Pada periode 16-22 Oktober 2019, terdapat sebanyak 74 tayangan berita dengan kata kunci 'Jokowi' yang disiarkan oleh METRO TV.

2) Total durasi seluruh tayangan METRO TV dengan kata kunci "Jokowi" periode 16-22 Oktober 2019 ialah 8 jam 30 menit 55 detik (510 menit 55 detik).

3) Selama menjelang pengumuman kabinet Indonesia Maju, ratarata berita METROTV dengan kata kunci "Jokowi” berdurasi 72 menit 36 detik per hari.

4) Terdapat sebanyak 63 tayangan yang memberikan bingkai positif tentang keputusan, kebijakan, keberhasilan dan/ kepribadian Jokowi.

5) Dari 63 tayangan yang berisi frame positif tentang Jokowi, terdapat 3 tayangan yang didalamnya juga mengandung frame negatif kausalitas (bersifat konsekuensi atas sikap politik Jokowi).

6) Sebanyak 9 tayangan hanya berisi pernyataan dari para calon menteri kabinet Indonesia Maju tanpa ada bingkai khusus dan/ bingkai langsung tentang Jokowi.

7) Hanya ada satu tayangan yang berisi frame negatif tentang peluang Jokowi memberikan kursi menteri kepada partai oposisi. 
8) Kata kunci "Jokowi" ditemukan diberbagai program acara METRO TV dengan waktu siar yang berbeda.

Adapun pergerakan frekuensi kemunculan kata kunci "Jokowi" pada tayangan berita METRO TV sebelum pengumuman Kabinet Indonesia Maju dapat dilihat pada grafik berikut ini:

Gambar 2. Grafik 1

Frekuensi Berita “Jokowi” Sebelum Pengumuman Kabinet

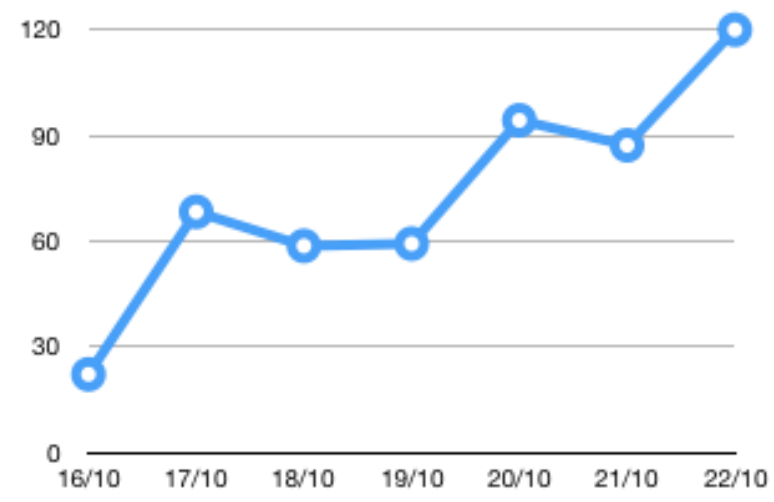

Pada 4 tayangan berdurasi 13-37 menit, redaksi METRO TV menghadirkan narasumber untuk memberikan pendapat mereka terkait peluang masuknya partai oposisi ke koalisi JokowiMa'ruf. Topik utama yang didiskusikan pada tayangan tersebut ialah konsekuensi yang mungkin terjadi apabila ada partai oposisi yang masuk ke koalisi, etika dalam melakukan manuver politik, dan saran untuk presiden Jokowi terkait susunan Kabinet Indonesia Maju. 
Pada tayangan-tayangan tesebut, presenter dan narasumber juga mendiskusikan pernyataan Surya Paloh, Ketua Dewan Pembina Partai Nasdem yang mengaku partainya siap untuk menjadi oposisi pemerintah apabila seluruh partai lainnya ingin berkoalisi dengan pemerintah. Selama tayangan program, redaksi cenderung menampilkan berulang-ulang pernyataan sekjen Partai Nasdem, Johnny G Plate, tentang dukungan penuh tanpa syarat Nasdem kepada presiden Jokowi sejak 2014.

\section{B. Berita "Jokowi" di METROTV setelah Pengumuman Kabinet}

Dalam Pemberitaan Jokowi di Metro TV setelah Pengumuman diperoleh data sebagai berikut:

1) Selama periode 23-30 Oktober 2019, terdapat sebanyak 29 tayangan berita dengan kata kunci 'Jokowi' yang disiarkan oleh METRO TV.

2) Total durasi seluruh tayangan METRO TV dengan kata kunci "Jokowi" periode 23-30 Oktober 2019 ialah 3 jam 14 menit 44 detik (194 menit 44 detik).

3) Setelah pengumuman kabinet Indonesia Maju, rata-rata berita METRO TV dengan kata kunci “Jokowi” berdurasi 27 menit 49 detik per hari.

4) Terdapat sebanyak 29 tayangan yang memberikan bingkai positif tentang keputusan, kebijakan, keberhasilan dan/ kepribadian Jokowi. 
5) Dari 29 tayangan yang berisi frame positif tentang Jokowi, terdapat 1 tayangan yang didalamnya juga mengandung frame negatif yang membahas tentang posisi milenial di kabinet Jokowi jilid II.

6) Pasca pengumuman kabinet Indonesia maju, tidak ada tayangan yang murni berisi bingkai negatif mengenai keputusan, kebijakan, dan/ kepribadian Jokowi.

7) Kunci "Jokowi" ditemukan diberbagai program acara METRO TV dengan waktu siar yang berbeda.

Adapun pergerakan frekuensi kemunculan kata kunci "Jokowi" pada tayangan berita METRO TV setelah pengumuman Kabinet Indonesia Maju dapat dilihat pada grafik berikut ini:

Gambar 3. Grafik 2

Frekuensi Berita "Jokowi” Setelah Pengumuman Kabinet

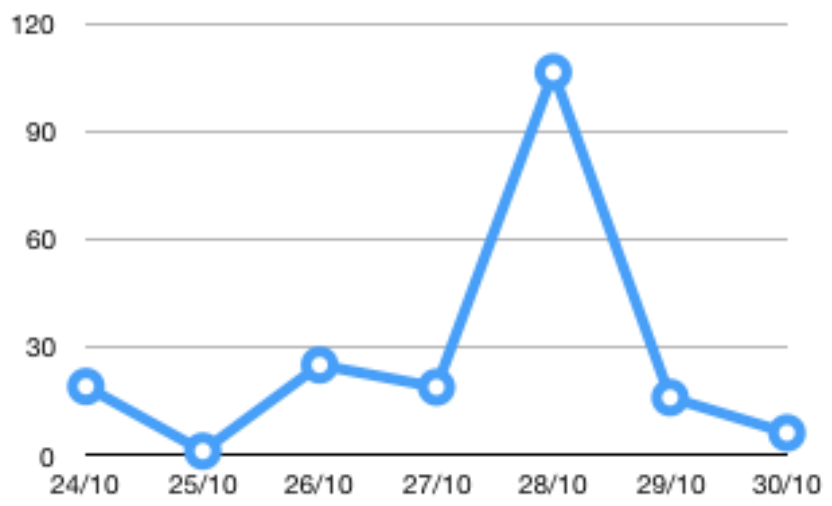


Berdasarkan grafik 2, diketahui pergerakan frekuensi kemunculan berita dengan kata kunci "Jokowi" cenderung fluktuatif tidak beraturan.

\section{Pembahasan isu dalam Perspektif Tanggung Jawab Sosial}

Berdasarkan data-data yang telah penulis jabarkan pada bagian sebelumnya diketahui bahwa frekuensi peredaran hoax di Indonesia mengalami peningkatan yang signifikan setiap tahunnya. Hasil studi dari Universitas Oxford serta laporan investigasi kolaborasi antara BBC dan Australian Strategic Policy Institute (ASPI) mengindikasi adanya keterlibatan pihak-pihak tertentu yang memanfaatkan media sosial untuk menyebarkan konten manipulatif. BBC dan ASPI juga mengekspos sejumlah unggahan dari akun-akun yang diduga robot. Adapun kontenkonten yang disebarkan oleh akun tersebut berisi pernyataan yang 'pro-Jakarta'. Diketahui juga sebanyak 100 akun yang terafiliasi dengan InsightID telah menghabiskan dana sebesar Rp 4,2 miliar untuk iklan tentang Papua di Facebook.

Pertanyaan yang muncul ialah apakah benar dana tersebut murni berasal dari kas InsightID yang berkantor di Jakarta itu? Jika tidak, siapa yang mendanai iklan tersebut? Dalam hal ini, di mana posisi pemerintah? Pasalnya, selama ini aparatur negara ramairamai menyalahkan hoax dan fake news sebagai penyebab kericuhan. Hasil studi, laporan investigasi, dan keterangan resmi dari Facebook memberikan perspektif baru bagi publik. Bukan hal 
yang mengherankan jika para ahli kemudian mulai menduga-duga keterlibatan pemerintah yang selama ini berperan sebagai salah satu korban.

Menariknya, hampir seluruh media massa nasional seolaholah resisten untuk mendiskusikan laporan investigasi BBC dan ASPI, serta keterangan pers dari Facebook tersebut. Berita yang muncul di sejumlah media massa tidak dalam dan cederung bersifat seremonial (pelengkap) saja, tidak ada followup atau kelanjutan dari kasus, tidak seperti berita tentang hoax yang banyak dibingkai sebagai penyebab kericuhan.

Sikap media tersebut memvalidasi analisis Temby dalam South China Morning Post (09/09/2019) yang menyatakan bias tayangan media mainstream Indonesia yang dianggap terlalu bersimpati kepada pemerintah sebagai salah satu penyebab penurunan kepercayaan publik terhadap media massa, dan menyebabkan peralihan sumber informasi ke media sosial. Adanya dukungan dari sejumlah pemilik korporasi media massa di Indonesia kepada calon presiden pertahana pada pemilihan presiden 2019 lalu membuat klaim Temby sulit untuk dibantah. Minimnya perhatian media massa nasional terhadap isu akun robot 'pro-Jakarta' juga dapat mengindikasikan ketidaknetralan media.

Diasumsikan bahwa faktor-faktor seperti pemilik media, penanam modal, pengiklan, dan regulasi pemerintah menentukan bagaimana media mengkonstruksi sebuah realitas. Ketentuanketentuan media meliputi peristiwa apa saja yang bisa atau tidak 
bisa ditampilkan dalam pemberitaan, atau ke mana kecenderungan pemberitaan itu hendak diarahkan. Dengan kata lain, konstruksi realitas (bingkai) yang diproduksi media mencerminkan keperpihakan dan arah politik dari media tersebut.

Dalam kasus berita dengan kata kunci "Jokowi" yang disiarkan METROTV misalnya, ada dugaan bahwa bingkai yang diciptakan tentang "Jokowi" dipengarui oleh sikap politik Surya Paloh sebagai pemilik Media Grup yang juga merupakan pendiri Partai NasDem. Perubahan situasi politik Indonesia pasca manuver Ketua Dewan Pembinan Partai Gerindra, Prabowo Subianto, yang bertemu dengan Jokowi menimbulkan perubahan pola-pola pemberitaan METRO TV yang cukup unik.

Seperti yang diketahui bersama, manuver politik Prabowo mendapat resistensi dari sejumlah pihak, khususnya Partai NasDem. Salah satu wujud dari resistensi tersebut tercermin dari pernyataan Surya Paloh saat menjawab pertanyaan para jurnalis di kompleks istana kepresidenan Jakarta (suara.com, 21/10/2019), "Tidak baik kalau tidak ada check and balances, jika tak ada lagi oposisi, demokrasi selesai. Negara cenderung akan otoriter dan monarki." Surya Paloh bahkan menyatakan siap keluar dari koalisi apabila nantinya tidak ada yang bersedia menjadi oposisi.

Resistensi Nasdem terhadap isu mengenai peluang Gerindra untuk bergabung ke koalisis Jokowi sudah disuarakan sejak Juli 2019. Sekretaris jenderal Partai Nasdem, Johnny G. Plate dalam (tirto.id, 23/07/2019) berpendapat bahwa tak ada manfaat yang 
bisa didapat saat PDIP memutuskan untuk mengajak gerbong oposisi Gerindra ke dalam Koalisi Indonesia Kerja (KIK).

Menyerupai sikap politik Partai Nasdem, pasca pertemuan Prabowo dengan Jokowi pada 11 Oktober 2019, ada kecenderungan berita METRO TV untuk mempengaruhi Presiden Jokowi dalam menyusun Kabinet Indonesia Maju. Menurut pandangan Edelman, media massa kengkonstruksi realitas melalui kategorisasi yang bertujuan untuk mengarahkan perspektif tertentu dengan menggunakan kata-kata yang tertentu pula. Dalam pandangan Eriyanto, media massa memiliki ideologi (nilai-nilai) yang disepakati bersama yang menjadi tolak ukur jurnalis dalam memproduksi berita.

Pada kasus berita dengan kata kunci "Jokowi" di METROTV, ada dugaan bahwa redaksi dengan sengaja memilih kata-kata tertentu untuk menciptakan bingkai positif tentang Jokowi. Namun demikian, ketika Prabowo melalukan manuver politik yang mendapatkan penolakan dari Surya Paloh, METROTV turut menanggapi peristiwa tersebut dengan menciptakan bingkai negatif (kausalitas). Seirama dengan sikap Partai Nasdem, redaksi METROTV berusaha membingkai sikap politik Prabowo sebagai tindakan yang tidak etis, serta mengundang 'ahli-ahli' untuk memprediksi dampak negatif yang mungkin muncul apabila Jokowi menerima Gerindra untuk masuk ke koalisi.

Konstruksi realitas yang berusaha menggiring opini publik tentang Prabowo dapat dilihat daari pertanyaan-pertanyaan yang 
diajukan oleh presenter Metro Pagi Primetime, Kevin Egan, yang disiarkan pada 19/10/2019. Berikut ini adalah pertanyaanpertanyaan yang diajukan Egan kepada pengamat politik Universitas Islam Negeri (UIN) Syarif Hidayatullah, Gun Gun Heryanto:

1. Haruskah orang yang berkeringat yang masuk kedalam kabinet?

2. Ada tidak efek buruk yang kemudian muncul kepada koalisi itu sendiri kalau ada partai-partai yang masuk belakangan?

3. Cara untuk Pak Jokowi memastikan bahwa partai-partai yang mungkin saja belakangan ini akan masuk, apakah cukup hanya dengan memberikan kursi menteri?

4. Untungnya untuk Pak Jokowi menggabungkan semua kedalam koalisi, kalau pun kita yakin bahwa dia sebetulnya tahu ada resiko itu sebetulnya ketika kemudian memasukkan Partai Gerindra, PAN, dan juga Demokrat untuk masuk, untungnya apa sebetulnya untuk Pak Jokowi?

Berikut ini ialah pertanyaan-pertanyaan yang Egan ajukan kepada Wasekjen PPP, Achmad Baidowi:

1. Tetap solid tidak nih PPP?

2. Tapi kalau ada partai yang belakangan masuk, Gerindra mau masuk, Demokrat juga, PAN bahkan mungkin diisukan juga masuk. Bagaimana?

3. Tetapi sikap PPP sendiri iklas tidak?

4. Tapi ada tidak yang bisa menjamin bahwa partai Gerinda, PAN, maupun Partai Demokrat yang mungkin masuk ke kabinet 
begitu saja, lalu kemudian bisa juga solid tidak hanya kemudian di kabinet tetapi juga kemudian di parlemen? Ada tidak kemudian bisa menjamin? Tidak kemudian nanti ada satu kaki di pemerintahan tapi kemudian kaki yang lain di luar pemerintahan? Bagaimana?

5. Itu terbukti pada pemerintahan jilid pertama ya?

6. Itu akan terjadi di PPP kurang lebih?

7. Ini tinggal esok pelantikan, informasinya kemungkinan kabinet juga akan diumumkan, tidak hanya besok tetapi juga hari-hari kedepannya, informasi terakhir seperti apa mas?

Dari pertanyaan-pertanyaan yang diajukan, diduga redaksi METROTV berusaha membingkai sikap politik Prabowo dan para petinggi partai lainnya yang ingin bergabung ke koalisi sebagai tindakan yang tidak etis. Rival Jokowi dianggap sebagai pihakpihak yang selama ini tidak berkeringat dalam memenangkan Jokowi. Oleh karena itu, masuknya partai oposisi ke koalisi berpotensi mengganggu soliditas partai koalisi.

Frekuensi penayangan berita dengan kata kunci "Jokowi" menjelang pengumuman kabinet Indonesia Maju mencapai 8 jam 30 menit 55 detik. Dari temuan tersebut, penulis menduga redaksi METROTV berupaya mempengaruhi keputusan Jokowi dalam menyusun Kabinet Indonesia Maju. Hal ini juga terlihat dari kecenderungan durasi yang lebih panjang untuk tayangantayangan yang berisi bingkai tentang Jokowi. Kemunculan bingkai 
tersebut diduga akibat adanya ketidakpuasan pendiri Partai Nasdem, Surya Paloh, dengan sikap politik Partai Gerindra.

Dugaan adanya upaya redaksi METROTV untuk mempengaruhi keputusan politik Jokowi juga dapat dilihat dari pemutaran pernyataan para politisi Partai Nasdem yang menolak peluang kehadiran Partai Gerindra di koalisi. Peryataan Surya Paloh yang mengaku siap menjadi oposisi juga cenderung dapat dikonotasikan sebagai bentuk tekanan politik terhadap Jokowi. Sementara itu, penulis menduga, fluktuasi frekuensi dan durasi tayangan berita dengan kata kunci "Jokowi" setelah pengumuman kabinet disebabkan karena belum adanya kepastian sikap Partai Nasdem terhadap pemerintah.

Dugaan ini muncul akibat sikap Ketua Umum Partai Nasdem yang enggan menjawab pertanyaan para jurnalis terkait kepuasan dirinya dengan susunan Kabinet Indonesia Maju. Berikut adalah kutipan jawaban dari Surya Paloh yang dilansir cnnindonesia.com (25/10/2019):

"Kepuasan itu kan relatif, tapi itu adalah suatu hal yang harus disyukuri," kata Paloh di Kompleks Istana Kepresidenan Jakarta, Jumat (25/12).

Paloh menyatakan pihaknya memberikan dukungan tanpa syarat kepada pemerintahan periode kedua Jokowi. Ia mengaku menerima seluruh konsekuensi dan akan tetap konsisten mendukung Jokowi yang kali ini didampingi Ma'ruf Amin.

"Bagaimanapun juga kinerja menteri-menteri NasDem jauh harus lebih baik di dalam Kabinet 
Indonesia Maju," ujarnya. Bos Media Group itu menyatakan kader NasDem yang diangkat menjadi menteri merupakan pilihan Jokowi. Menurutnya, Jokowi tetap berkoordinasi dengan dirinya saat memutuskan untuk memilih tiga kadernya.

Terlepas ada atau tidaknya instruksi langsung dari pemilik media tentang batasan-batasan apa yang dapat dan tidak dapat ditayangkan di METRO TV, penulis menduga dalam mengkonstruksi realitas tentang politik, khususnya yang terkait dengan Jokowi, redaksi berusaha untuk berada sedekat mungkin dengan sikap politik pemilik media, Surya Paloh.

Temby dalam South China Morning Post (09/09/2019) menyatakan, penurunan tingkat kepercayaan publik atas informasi yang disampaikan oleh media massa mainstream mengindikasikan kegagalan sejumlah media massa di Indonesia dalam menjalankan fungsinya. Salah satu fungsi utama media ialah sebagai pendidik dan pengawas kebijakan publik. Ketika media massa memproduksi berita yang bias, konsekuensinya sudah tentu akan ditinggalkan publik. Karena pilihan alternatif yang tersisa hanyalah media sosial, maka sangat logis apabila masyarakat beralih ke media sosial untuk memperoleh informasi.

Sayangnya, kemampuan literasi yang rendah membuat masyarakat Indonesia rentan terprovokasi. Media sosial menjadi lebih berbahaya dari media mainstream karena konten yang tersebar lebih sulit untuk dipertanggung jawabkan kebenarannya. Sementara itu, karakteristik penduduk yang heterogen membuat 
masyarakat Indonesia lebih reaktif terhadap isu-isu yang berkaitan dengan SARA (suku, agama, ras, dan antar golongan).

Laporan investigasi kolaborasi antara BBC dan Australian Strategic Policy Institute (ASPI) serta keterangan pers Facebook yang mengekspos ratusan akun robot "pro-Jakarta" perlu menjadi pengingat untuk seluruh pihak, khususnya pekerja media mainstream akan bahaya media sosial. Berdasarkan data-data dari hasil studi pustaka yang telah penulis jabarkan pada bagian sebelumnya, diketahui bahwa frekuensi rata-rata peredaran hoax per bulan pada periode 2015-2018 mengalami penginkatan signifikan hingga \pm 2 kali lipat setiap tahunnya. Hal ini memvalidasi kecurigaan terkait adanya pemanfaatan media sosial untuk menyebarkan fake news. Fenomena kericuhan di Indonesia yang diduga akibat disinformasi online dapat dijadikan salah satu bukti empiris. Hasil penelitian yang menunjukkan ketidakmampuan sekitar 112 dari 184 mahasiswa Indonesia untuk mengidentifikasi fake news juga perlu mendapatkan perhatian serius.

Sejumlah negara seperti Amerika Serikat, Canada, Inggris, dll. sudah memasukkan mata pelajaran Literasi Media kedalam kurikulum pendidikan (Common Sense Media dan California Department of Education, 19/09/2019). Bahkan sejak tahun ajaran 2018/2019, Departemen Pendidikan California telah memberlakukan kurikulum Literasi Media untuk siswa/siswi taman kanak-kanak hingga kelas 12. Sejumlah pihak berpendapat 
bahwa di Indonesia program literasi sudah diajarkan pada mata pelajaran kewarganegaraan.

Penulis menyetujuan adanya kurikulum kewarganegaraan sebagaimana yang direkomendasikan oleh UNESCO. Menurut Gagliardon dalam Santoso (2016:92-93), pendekatan literasi media versi UNESCO ialah melalui pendidikan kewarganegaraan (citizenship education) dan kewargaan digital (digital citizenship). Adapun tujuannya adalah salah satu upaya melawan pesan kebencian (hate speech). Jika demikian, yang perlu dicermati kembali ialah metode pengajaran dan/ kemampuan pengajar. Pasalnya, jika melihat dari kecederungan data-data yang ada, tingkat literasi di Indonesia masih cukup rendah. Artinya, ada yang perlu dievaluasi dari metode pengajaran dan/ topik bahasan dalam pendidikan kewarganegaraan yang sudah ada.

Namun demikian, terlepas dari ada atau tidaknya kurikulum tambahan yang khusus membahas tentang literasi budaya, digital, media, dan politik, peran publik juga dibutuhkan. Sebagai bagian dari sistem sosial, publik sering kali dibingkai sebagai korban, sementara pemerintah dan perusahaan media sosial dibingkai sebagai pihak yang bertanggungjawab dalam upaya melawan hoax dan fake news.

Dalam perspektif tanggung jawab sosial, asumsi tindakan tersebut kurang tepat. Begitu pun juga pernyataan yang sepenuhnya menyalahkan bias media mainstream. Jika setiap sistem sosial harus menjalankan fungsinya untuk memberikan 
manfaat bagi sistem sosial lain, maka sebagai bagian dari sistem sosial, publik juga memiliki tanggung jawab yang sama dalam memerangi hoax dan fake news.

\section{KESIMPULAN DAN SARAN}

Dalam dunia bisnis khususnya media massa, tanggung jawab sosial dideskripsikan sebagai kumpulan kewajiban media massa dan/ organisasi lainnya untuk menjalankan dan mempertanggung jawabkan fungsinya kepada publik. Begitu pun dalam dunia politik, tanggung jawab sosial dilihat sebagai kewajiban aparatur negara dalam menjalankan dan mempertanggung jawabkan fingsinya kepada masyarakat. Yang sering dilupakan ialah publik juga bagian dari sistem sosial, artinya publik juga memiliki tanggung jawab dalam menyelesaikan permasalahan sosial.

Berdasarkan temuan-temuan dari penelitian terdahulu, ada kecederungan peningkatan popularitas hoax dan fake news setiap tahunnya. Oleh karena itu, diperlukan kesungguhan pemerintah untuk merancang strategi baru dalam upaya memerangi peredaran hoax dan fake news di Indonesia. Salah satunya mungkin dengan membuat kurikulum tambahan yang mendorong kultur literasi. Kurikulim literasi media dan teknologi misalnya, melalui program ini masyarakat tidak hanya dapat meningkatkan keterampilan dalam menggunakan perangkat teknologi telekomunikasi, tetapi juga dapat mempelajari cara-cara identifikasi hoax dan fake news di media sosial. Penulis meyakini bahwa cara ini akan lebih murah 
daripada mengangkat lebih banyak aparatur negara untuk mengendalikan hoax.

Melihat tren yang ada, agaknya eksistensi hoax dan fake news, khususnya di Indonesia, akan sulit untuk diberantas sepenuhnya. Untuk itu, media massa mainstream perlu mendefinisikan ulang orientasi kerja mereka sebagai bagian dari sistem sosial. Mungkin dapat dimulai dari meningkatkan kepercayaan publik melalui tayangan-tayangan yang lebih edukatif dan kritis. Sementara itu, perusahaan media sosial juga perlu berperan lebih aktif dalam menghapus dan/ menonaktifkan akun-akun penyebar hoax dan fake news. Di saat yang sama, masyarakat Indonesia perlu mengedukasi diri, meningkatkan pemahaman dan memperluas pengetahuan secara mandiri.

Jika Indonesia dianalogokan sebagai sebuah sepedah, maka setiap bagian dari sepedah perlu berfungsi dengan baik untuk dapat memberikan nilai tambah bagi kehidupan. Jika tidak, sepedah tidak dapat bermanfaat sebagaimana tujuan pembuatannya. Sepedah tanpa rantai tidak dapat dikayuh, tanpa jok tidak dapat diduduki, tanpa handlebar (stang) akan sulit diarahkan. Sebagaimana sepedah, sistem sosial masyarakat Indonesia perlu menjalankan fungsinya masing-masing agar tencipta budaya literasi yang terintegrasi.

Pemerintah perlu dengan tegas menindaklanjuti produsen dan distributor hoax dan fake news, serta menerapkan kurikulum literasi sejak dini. Media massa perlu untuk lebih independen dan 
berimbang serta menjalankan fungsi kontrol. Perusahaan media sosial perlu untuk lebih mengedepankan kepentingan publik dari pada kepentingan bisnisnya. Publik perlu mengedukasi diri terkait cara-cara mengidentifikasi hoax dan fake news. 


\section{DAFTAR PUSTAKA}

Aisah, Hasnini Hasra, dan Ati Sumiati. 2019. Developing Model of Media Literacythrough Critical Analysis of Fake News. Jurnal International Seminar on Languages, Literature, Arts, and Education (ISLLAE), vol. 1 (1), hal 109-115. journal.unj.ac.id/isllae/article/view/10942/7257

Bastani, Alireza, Tahmures Shiri, dan Aliakbar Farhangi. 2019. The Necessity of Media Knowledge Education to Students to Promote their Media Literacy Competency. International Journal of Social Sciences (IJSS), vol. 9 (1), hal 41-56. ijss.srbiau.ac.ir/article_14257.pdf.

Cardinale, Ivano, dan Roberto Scazzieri. 2018. The Palgrave Handbook of Political Economy. Berlin: Springer. books.google.ae/books?id=zTppDwAAQBAJ\&.

Carsrud, Alan L., dan Malin Brännback. 2007. Entrepreneurship. Connecticut: Greenwood Publishing Group.

Eriyanto. 2012. Analisis Framing: Konstruksi, Ideologi, dan Politik Media. Yogyakarta: LKiS Yogyakarta. google.com/books/Entrepreneurship/GTybgv_8GrMC?hl.

Fauzi, Ahmad. 2018. Memahami Literasi Media Baru dalam Penyebaran Informasi Hoax dan hate speech (Studi Fenomenologi Dosen Pengguna Facebook dan Whatsapp). PROMEDIA, vol. 4 (2), hal. 56-76. journal.uta45jakarta.ac.id/article/1192/898.

Folkens, Lukas, dan Petra Schneider. 2019. Social Responsibility and Sustainability: How Companies and Organizations Understand Their Sustainability Reporting Obligations. World Sustainability Series (WSUSE), hal. 159-188. springer.com/10.1007/978-3-030.

Herawati, Dewi Maria. 2016. Penyebaran Hoax dan Hate Speech sebagai Representasi Kebebasan Berpendapat. PROMEDIA, vol. II (2), hal. 138-155. journal.uta45jakarta.ac.id/article/793/510.

Herlina, Mira, dan Safarudin Husada. 2019. Dampak Kejahatan Cyber dan Informasi Hoax Terhadap Kecemasan Remaja di Media Online. PROMEDIA, vol. 4 (2), hal. 56-76. journal.uta45jakarta.ac.id/article/1192/898. 
Lailiyah, Nuriyatul, Much. Yulianto, dan Ghozian Aulia Pradhana. 2018. Youthizen, Political Literacy, and Social Media. ICENIS 2018, vol. 73, 14005, hal. 1-4. e3s-conferences.org/e3sconf/pdf/48/icenis18. Mason, Lance E., Daniel G. Krutka, dan Jeremy Stoddard. 2018. Media Literacy, Democracy, and the Challenge of Fake News. Journal of Media Literacy Education 10 (2), hal. 1-10. digitalcommons. uri.edu/article $=1389 \&$ context. Mulyana, Deddy. 2012. Cultures And Communication: An Indonesian Scholar's Perspective. Bandung: Remaja Rosdakarya Offset. google.ae/books?id=nUxODwAA. Mudjiyanto, Bambang. 2019. Kebebasan Berekspresi dan Hoaks. PROMEDIA, vol. 5 (1), hal. 1-39. journal.uta45jakarta.ac.id/article/1613/1115.

Pratiwi, Anggi, dan Eflinnida Nurul Komaril Asyarotin. 2019. Implementasi literasi budaya dan kewargaan sebagai solusi disinformasi pada generasi millennial di Indonesia. Jurnal Kajian Informasi \& Perpustakaan, vol. 7 (1), hal. 6580. http://jurnal.unpad.ac.id/jkip/article/view/20066.

Santoso, Edi. 2016. Pengendalian Pesan Kebencian (Hate Speech) di Media Baru Melalui Peningkatan Literasi Media. Jurnal FISIP Unila, Prosiding Seminar Nasional Komunikasi, hal. 88-94.

Siebert, Fred, et al. 1956. Four Theories of the Press: The Authoritarian, Libertarian, Social Responsibility, and Soviet Communist Concepts of What the Press Should Be and Do. Illinois: University of Illinois Press, 1956. google.ae/books?id=4Q-oePDdc. jurnal.fisip.unila.ac.id/article/274/175.

Sudibyo, Agus. 2000. Absennya Pendekatan Ekonomi Politik Untuk Studi Media. Jurnal Ilmu Sosial dan Ilmu Politik UGM, vol. 4 (2); 115-34, 2000. https://jurnal.ugm.ac.id/jsp/article/view/11116.

Wardhani, Primandha Sukma Nur. 2018. Partisipasi Politik

Pemilih Pemula dalam Pemilihan Umum. Jurnal Pendidikan Ilmu-Ilmu Sosial, vol. 10 (1), hal. 57-62. jurnal.unimed.ac.id/2012/article/8407/9060. 


\section{Sumber Lain}

AFP/nh. (26/06/2019). CNA. Indonesian police beat protesters during deadly Jakarta riots: Amnesty. channelnewsasia.com/asia/indonesia-11663668.

Agency, AFP News. (29/10/2019). Aljazeera. Rights group: 10 unlawfully killed in Indonesia election riots. aljazeera.com/2019/10/191029.html.

Amirullah, dan Syafiul Hadi. (10/08/2018). Tempo. Tiga Pemilik Media Massa di Barisan Pendukung Jokowi. nasional.tempo.co/1125147/page_num=3.

Banjo, Shelly. (02/10/2019). The Washington Post. Facebook, Twitter and the Digital Disinformation Mess. washingtonpost.com/business/3d03721b85ef_story.html.

Davies, Ed, and Stanley Widianto. (17/11/2019). Reuters. RPTIndonesia needs to urgently establish data protection lawminister. reuters.com/article/idUSL4N27Y0MA.

FRA/WIS. (25/10/2019). CNN Indonesia. Surya Paloh Bersyukur NasDem dapat Tiga Menteri dari Jokowi. cnnindonesia.com/nasional/20191025183237.

Herman/FER. (15/03/2019). Berita Satu. Hoax Makin Marak, BSSN Minta Penyedia Platform Medsos Bertindak. beritasatu.com/digital/543101/hoax-makin-marak.

Jannah, Selfie Miftahul. (22/05/2019). Tirto.id. Nasdem: Tak Ada Manfaatnya Prabowo Gabung Koalisi Jokowi. tirto.id/nasdem-tak-ada-manfaatnya.

Lamb, Kate. (22/05/2019). The Guardian. Jakarta riots: Indonesian president says he will not tolerate threats to unity. theguardian.com/world/2019/may/23/indonesia.

Lesmana, Agung Sandy. (21/10/2019). Suara.com. Surya Paloh: Kalau Tak Ada yang Mau Jadi Oposisi, Biar Nasdem Saja. suara.com/news/2019/10/21/155648.

Reuters. (08/11/2019). India Today. Today we stand on Indonesian land corrupted by oligarchy: Student protests rock Indonesia. indiatoday.in/world/story/51-2019-11-08.

Reuters. (10/11/2019). The Jarusalem Post. Anger on campus: Behind the student protests that have rocked Indonesia. jpost.com/International/607366. 
RNZ. (24/10/2019). Radio New Zealand. Indonesian human rights lawyer wins prize for West Papua work. rnz.co.nz/international/401682/indonesian-human-rights.

Strick, Benjamin, dan Famega Syavira. (11/10/2019). BBC News. Papua unrest: Social media bots 'skewing the narrative'. bbc.com/news/world-asia-49983667.

Taylor, Alan. (23/05/2019). The Atlantic. Photos: Deadly Postelection Riots in Indonesia. theatlantic.com/photo/2019/05/indonesia/590134/.

Tehusijarana, Karina M. (29/05/2019). The Straits Times. Who was behind the Jakarta riots? straitstimes.com/asia/who-was-behind-the-jakarta-riots.

Temby, Quinton. (09/09/2019). South China Morning Post. Indonesia's election riots offer a lesson on the perils of fake news. scmp.com/asia/politics/article/3026057.

Walden, Max. (25/10/2018). VOA. Ahead of 2019 Election, Indonesia, Media Battle Fake News. voanews.com/asia-pacific/ahead-2019-election-indonesia.

Widianto, Stanley. (28/05/2019). VOA. Police Violence in Indonesian Riots Sparks Human Rights Debate. voanews.com/asia-pacific/police-violence-indonesia.

Egan, Kevin. Presenter. (19/10/2019). METROTV. Polemik Pemilihan Menteri yang 'Berkeringat' dan 'Tidak' Dalam Sukseskan Jokowi-Ma'ruf. youtube.com/BnvfFViQ-Us\&t.

California Department of Education. Teaching \& Learning. https://www.cde.ca.gov/ci/cr/ml/.

Common Sense Media. About us. commonsensemedia.org/about-us. 